\title{
In Memorium: Ramon James Evans (1932-2007)
}

\author{
Men of Harlech stand ye steady \\ It cannot be ever said ye \\ For the battle were not ready \\ Stand and never yield..* \\ *old Welsh melody, Men of Harlech, words from the film Zulu
}

\begin{abstract}
Ray was well versed in the use of a variety of pharmacotherapeutic agents, including opioids, and was also an expert in neurolytic blocking procedures and in the indications for other neuroablative techniques, such as percutaneous cordotomy, which was performed frequently and very successfully by Ron Tasker more extensively when pharmacotherapy was more limited.

The yearly Smythe Pain Fellowship supported a variety of postgraduate Fellows from around the world who benefited from
\end{abstract} Ray's tutelage. These included, among others, Irma Guerera (Venezuela); Mark Taylor (United Kingdom); Perry Fine (United States); Connie Bubela (Canada); Linda Robinson (Ottawa), Warren Goldstein (Toronto), as well as myself. I (CPNW) remained with Ray for 12 years at the Smythe where we worked closely in patient care, teaching and research.

Ray was the best clinical mentor I ever had, and he taught me nearly all I know about pain assessment and management. He frequently obtained historical details previously unrevealed because he knew the right questions to ask and included the emotional aspects of chronic pain disorders. He performed the most thorough physical examinations I have ever seen, frequently discovering previously unrecognized and important signs.

He knew the natural history of metastatic cancers of all types and the kind of pain prob-
Ray in 1964 with his trademark bowtie on arrival in Canada Alberta.

Due to his interest in pain, in 1966 he accepted a fellowship position in pain research at the University of Toronto and later that year was appointed as director of the Irene Eleanor Smythe Pain Clinic at the University of Toronto, based at the Toronto General and Princess Margaret Hospitals. This clinic was financed by Conn Smythe after the death of his wife Irene Eleanor from cancer. It came under the auspices of the Department of Anesthesia, initially headed by Rod Gordon and later by Arthur Scott.

Ray applied his extensive clinical knowledge to the assessment and treatment of a broad spectrum of very difficult inpatients and outpatients with chronic noncancer pain. At the Toronto General and the Princess Margaret Hospitals, he also assessed patients with intractable pain due to

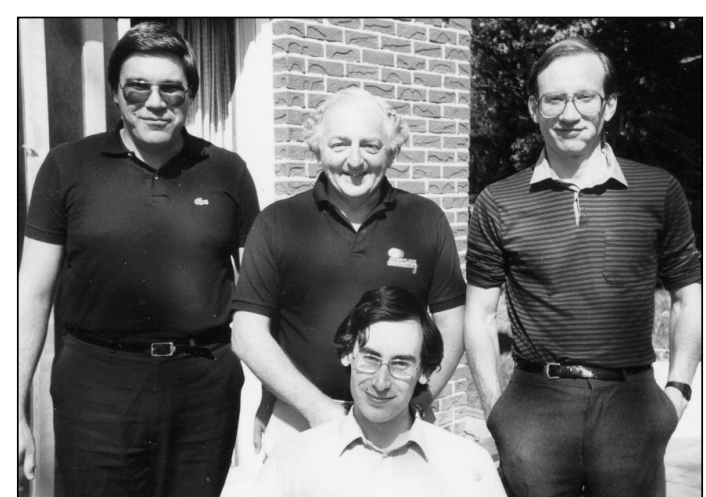

Ray as I knew him with Connie Bubela to his right, Mark Taylor, Fellow from England in front and Peter Watson to his left lems they produced. Because of his attention to details, such as skin temperature, he described the 'hot foot syndrome' of early sympathetic deafferentation, which can be the harbinger of early recurrence of pelvic cancers such as carcinomas of the cervix, bladder and rectum. His clinical judgement regarding treatment options was impeccable. He kept extensive clinical records that became part of a computer database. He was widely respected, as evidenced by patients coming from all over Canada.

Ray was President of the Canadian Pain Society from 1979 to 1982 . He knew many of the founding fathers of the International Association for the Study of Pain and we had frequent visitors from all over the world at the clinic.

He retired in 1997 at 65 years of with Iain Mackay (anesthesia), Ronald Tasker (neurosurgery), Jerry Friedman (psychiatry), Klaus Kuch (psychiatry) and others in all specialties collaborating to relieve these difficult pain problems. age, and travelled frequently to his house in Wales and enjoyed several leisure pursuits. Ray is survived by his wife Anne and his children Sarah, David and John, and grandchildren Emily Anne and Sawyer June.

Correspondence: Dr C Peter N Watson, Department of Medicine, University of Toronto, Toronto, Ontario. Telephone 416-239-3494,

fax 416-239-3494, e-mail peter.watson@utoronto.ca 


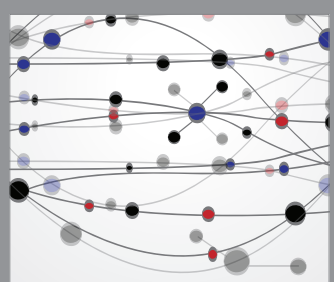

The Scientific World Journal
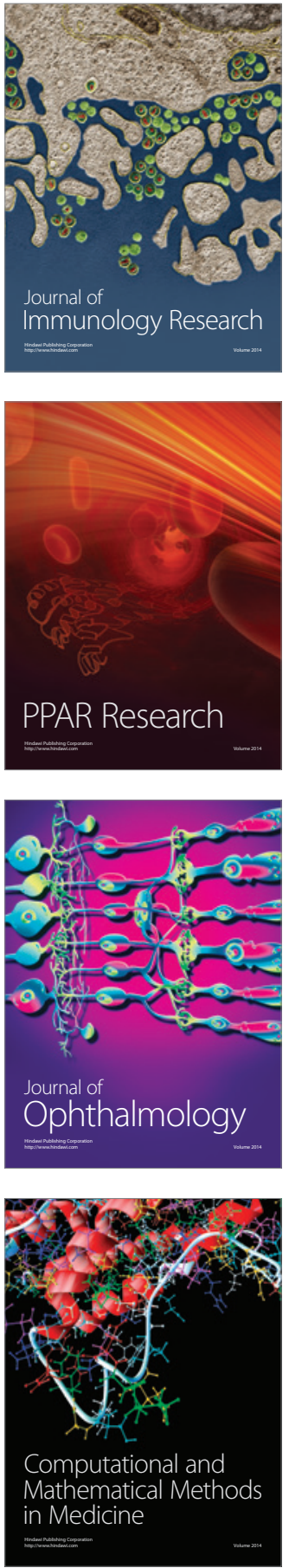

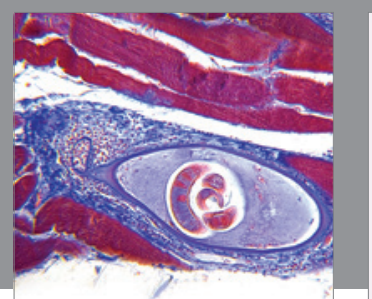

Gastroenterology Research and Practice

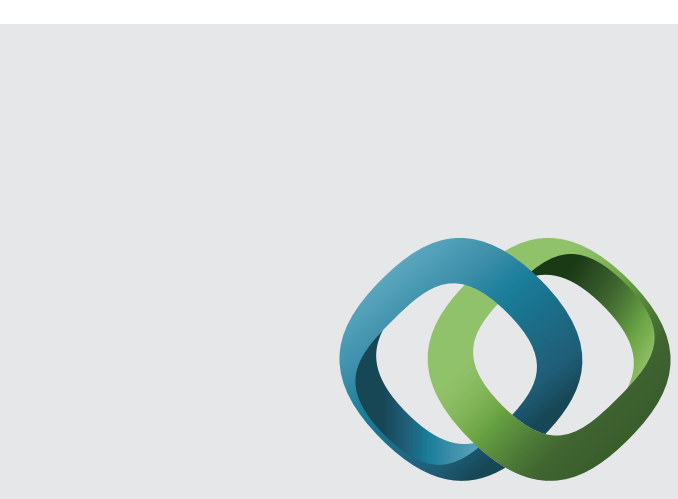

\section{Hindawi}

Submit your manuscripts at

http://www.hindawi.com
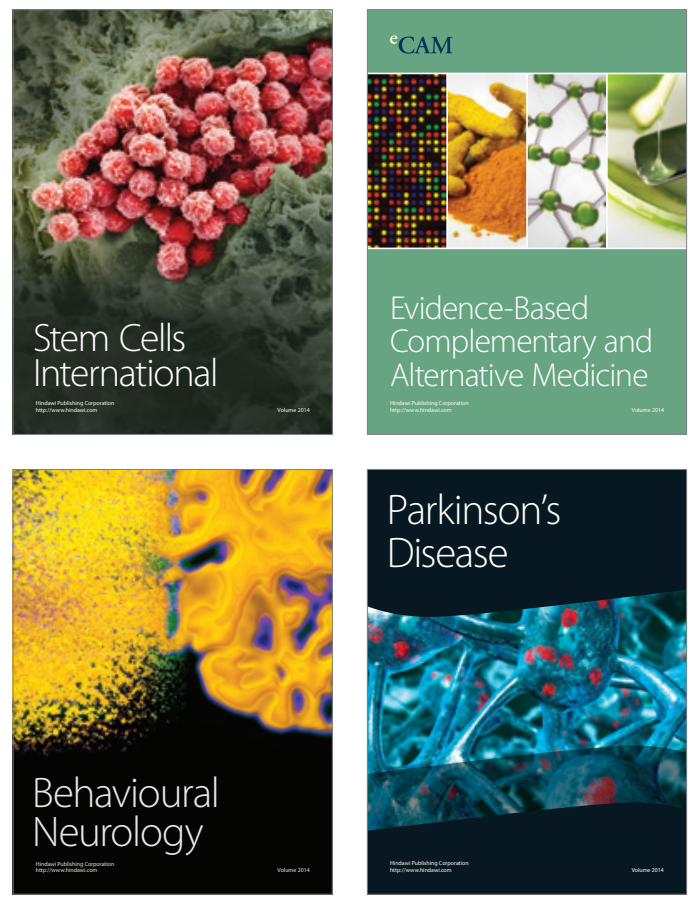
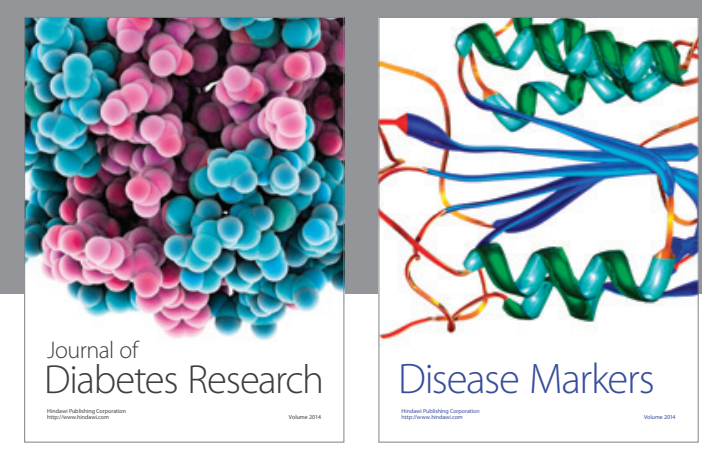

Disease Markers
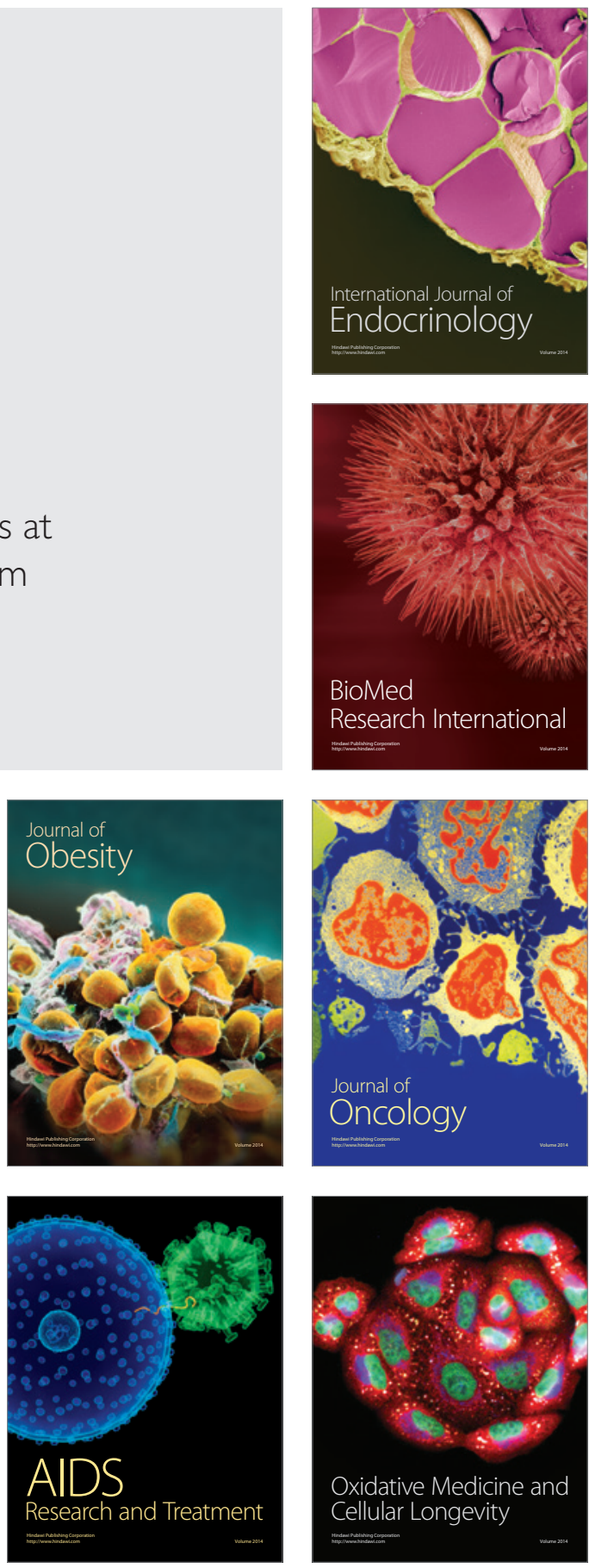